\title{
MLPA - first-tier Screening Assay in Newborns with Nonsyndromic Congenital Heart Disease
}

\begin{abstract}
ELENA MOLDOVAN ${ }^{1}$, VALERIU MOLDOVAN ${ }^{2 *}$, CLAUDIA BANESCU ${ }^{3}$, LUCIAN PUSCASIU ${ }^{4}$, MANUELA CUCEREA ${ }^{5}$

${ }^{1}$ Pediatric Intensive Care Unit, Cardiovascular and Transplant Emergency Institute of Targu Mures, 50 Gheorghe Marinescu Str., 540136, Targu Mures, Romania

${ }^{2}$ University of Medicine, Pharmacy, Sciences and Technology of Targu Mures, Center for Advanced Medical and Pharmaceutical Research, 38 Gheorghe Marinescu Str., 540139, Targu Mures, Romania

${ }^{3}$ University of Medicine, Pharmacy, Sciences and Technology of Targu Mures, Genetics Department, 38 Gheorghe Marinescu Str., 540139, Targu Mures, Romania

${ }^{4}$ University of Medicine, Pharmacy, Sciences and Technology of Targu Mures, Obstetrics and Gynecology Department, 38 Gheorghe Marinescu Str., 540139, Targu Mures, Romania

${ }^{5}$ Neonatology Department, University of Medicine, Pharmacy, Sciences and Technology of Targu Mures, 38 Gheorghe Marinescu Str., 540139, Targu Mures, Romania

Congenital heart disease (CHD) is the most frequent malformative pathology seen in newborns, with an incidence of 10/1000 births, and is considered a major cause of neonatal morbidity and mortality. About one third of congenital heart disease cases are of genetic origin, particular copy number variations being described as possible nonsyndromic and syndromic congenital heart disease causes. Here, we set out to find whether the MLPA technique could be used as a first-tier screening assay in newborns with apparently nonsyndromic CHDs, and thus to genetically confirm the CHD diagnosis. The study cohort included 60 newborns diagnosed with apparently nonsyndromic congenital heart disease, recruited for a period of 18 months. MLPA analysis was performed using the SALSA MLPA P311 and P250 kits. 10 newborns (16.67\%) showed known genetically relevant copy number variations, namely three patients with 22 q11.21 deletion, that were diagnosed with DiGeorge syndrome, and seven patients with a probable single exon $8 p 23.1$ duplication that will be subjected to further molecular testing, in order to correctly assess their diagnosis. We can conclude that the screening of patients with apparently nonsyndromic congenital heart disease may lead to their early and correct diagnosis, and thus them benefitting from the detection of clinically relevant copy number variations using the MLPA technique.
\end{abstract}

Keywords: MLPA, newborn, congenital heart disease, DiGeorge syndrome, 22q11.21 deletion

Congenital heart disease (CHD) is the most frequent malformative pathology seen in newborns, with an incidence of 10/1000 births [1]. Part of a genetic syndrome, or stand alone, CHDs are considered a major cause of morbidity and mortality, as $24-50 \%$ of neonates who die because of a birth defect actually have a heart defect $[2,3]$.

About one third of CHDs are of genetic [4] (such as chromosome abnormalities and single gene disorders) and epigenetic origin, the rest being of unknown etiology, possibly environmental and multifactorial. Since several important phenotypic changes seen in syndromic conditions, such as developmental delay or dysmorphic facial features are usually not apparent in neonates, a heart defect may be the first symptom seen at this age and thus the investigation of its etiology is extremely important, leading to a correct early diagnosis and appropriate treatment. The American Heart Association's 2007 scientific statement indicated four reasons that highlighted the importance of determining the genetic cause of the child's heart defect, as follows: (a) other important organ systems may be involved; (b) possible clinical prognosis information; (c) the genetic reproductive-related risk may be increased within the family; (d) the same genetic testing may be appropriate for other family members [5].

The full extent of copy number variation (CNV) implication in the occurrence mechanism of CHDs is not entirely known, although CNVs have been described as possible CHD causes, being found in both nonsyndromic and syndromic cases [6]. Unfortunately, only a fraction of patients harboring large gDNA alterations can be diagnosed by standard cytogenetic techniques, due to the thechniques' limited cytogenetic resolution $(5-10 \mathrm{Mb})$ [7], therefore higher resolution molecular techniques have to be used. Multiplex ligation-dependent probe amplification (MLPA) is a valuable tool for the

*email: valeriu.moldovan@umfst.ro 
detection of known CNVs, with a relatively low cost and a straightforward technique. The MLPA method has been previously used to diagnose CHDs in children, but not in neonates, and the diagnosis rate varied $[1,6,8]$, being mainly dependent on patient selection and the MLPA kit used.

In the present study we set out to find whether CNV testing, namely the MLPA technique could be used as a first-tier screening assay in newborns with apparently nonsyndromic CHDs, and thus to confirm clinical CHD diagnosis.

\section{Experimental part}

\section{Material and methods}

The study cohort included newborns diagnosed with apparently nonsyndromic CHDs, recruited from a tertiary neonatal intensive care unit from central Romania, from January 2016 to May 2018, for a period of 18 months. Patients exhibiting only minor heart defects, such as atrial and/or ventricular septal defects were not included in the present study. Additional exclusion criteria included children coming from diabetic mothers (including gestational diabetes) and mothers diagnosed with systemic diseases, as well as obesity. Patients' clinical assessment included the evaluation of CHD familial history. Cardiac assessment consisted in transthoracic echocardiography and chest X-ray.

The study protocol was approved by the ethics committee of the local medicine university and of the county hospital, and was carried out in accordance with their recommendations. An informed consent was obtained from all subjects' parents or legal guardians, according to the World Medical Association Declaration of Helsinki, revised in 2000, Edinburgh.

Genomic DNA was isolated from peripheral blood leukocytes using the PureLink Genomic DNA Mini Kit (Thermo Fisher Scientific, Waltham, USA).

gDNA was amplified using a Veriti Thermal Cycler (Applied Biosystem, Foster City, USA) and MLPA analysis was performed using the SALSA MLPA P311 and P250 kits (MRC-Holland, Amsterdam, The Netherlands) according to the manufacturer's protocol. The SALSA MLPA P311 kit amplifies 6 coding exons of GATA4 and 2 additional probes upstream of GATA4, as well as one CTSB-9, downstream of GATA4, corresponding to chromosome band 8p23.1, the 2 exons of $N K X 2-5$, corresponding to chromosome band 5q35.1, 7 of the 10 exons of $T B X 5$ and one intron, corresponding to chromosome band 12q24.21, 3 exons of BMP4 and one intron, corresponding to chromosome band 14q22.2, 2 exons of CRELD1 corresponding to chromosome band 3p25.3 and three probes in the 22q11 region. Patients positive for 22q11.2 deletion syndrome were further tested with the SALSA MLPA P250 kit for diagnosis confirmation. This kit contains probes for the detection of CNVs in the 4q, 8p, 9q, 10p, 17p, 22q11.2 and 22q13 regions and can be used to diagnose DiGeorge syndrome, DiGeorge syndrome type II as well as other disorders associated with deletions/duplications in these regions.

MLPA products were subjected to capillary electrophoresis using a 3500xL Dx Genetic Analyzer (Applied Biosystem, Foster City, USA) with a 50-cm 24 capillary array using POP7 polymer. Data were collected using the Gene Mapper software (Applied Biosystem) and later interpreted with the help of Coffalyser software (MRC-Holland). Abnormal profiles were discarded, and these patients were retested from the initial DNA sample. Ten unrelated control DNA samples were included as a reference population, and based on their results, patients in the $0.7-1.3$ category were considered to have two gene copies.

\section{Results and discusisons}

A total of 60 patients were included in the present study, 19 (31.7\%) females and $41(68.3 \%)$ males, none of them having any first-degree relatives diagnosed with CHDs.

The cardiac phenotype consisted in the following defects: transposition of great arteries (18 cases, 30\%), coarctation of the aorta (18 cases, 30\%), pulmonary valve atresia/stenosis ( 8 cases, 13,3\%), tricuspid valve atresia/stenosis (4 cases, $6.7 \%$ ), aortic stenosis ( 3 cases, $5 \%$ ), hypoplastic left heart syndrome ( 2 cases, $3,3 \%)$, common arterial trunk $(2$ cases, $3,3 \%)$, total anomalous pulmonary venous drainage (1 case, 1.7\%), persistent ductus arteriosus (1 case, 1.7\%), left coronary artery to coronary sinus fistula (1 case, 1.7\%), complete atrioventricular canal defect (1 case, 1.7\%) and aortopulmonary fenestration ( 1 case, $1.7 \%$ ).

In 45 cases Prostaglandin E1 treatment was introduced to maintain the permeability of the ductus arteriosus until the optimum surgery moment, as follows: in 23 cases the systemic circulation was ductal dependent, while in 22 cases pulmonary circulation was dependent on the patency of the arterial ductus.

Pregnancy ultrasound monitoring diagnosed 53.3\% of included cases with CHD before birth, while in 7 cases (11.7\%) the pregnancy was not monitored.

The mean birth weight was 3107 grams (1840grams-5100grams), 28.3\% were small for gestational age (SGA), 3.3\% large for gestational age (LGA) and $68.4 \%$ had a normal weight (AGA), according to Lubchenco [9] intrauterine growth 
curves. In our study, 10 newborns were premature, the rest having the gestation age between 37 and 42 weeks. None of them was postmature.

After MLPA analysis, 10 newborns (16.67\%) showed the copy number abnormalities presented in Table 1.

Table 1

COPY NUMBER ABNORMALITIES IDENTIFIED IN OUR PATIENTS AFTER MLPA ANALYSIS GENDER: F-FEMALE, M-MALE;

BIRTH WEIGHT: AGA-APPROPRIATE FOR GESTATIONAL AGE 2500grams-4000grams, SGA-Small FOR GESTATIONAL AGE <2500grams, LGA-LARGE FOR GESTATIONAL AGE >4000grams

\begin{tabular}{|c|c|c|c|c|c|c|}
\hline $\begin{array}{l}\text { Patient no. } \\
\text { and gender }\end{array}$ & Imbalance & Chromosome band & $\begin{array}{l}\text { Cardiac } \\
\text { phenotype }\end{array}$ & $\begin{array}{l}\text { Associated } \\
\text { malformations/ } \\
\text { pathologies }\end{array}$ & $\begin{array}{l}\text { Birth } \\
\text { Weight }\end{array}$ & Decease \\
\hline $22, \mathrm{f}$ & deletion & $22 q 11.21$ & $\begin{array}{c}\text { coarctation of the } \\
\text { aorta }\end{array}$ & ventriculomegaly & SGA & yes, postoperative \\
\hline $49, m$ & deletion & $22 q 11.21$ & $\begin{array}{c}\text { coarctation of the } \\
\text { aorta }\end{array}$ & hepatic cyst & LGA & no \\
\hline $57, \mathrm{f}$ & deletion & $22 q 11.21$ & $\begin{array}{c}\text { coarctation of the } \\
\text { aorta }\end{array}$ & none & AGA & no \\
\hline $32, \mathrm{f}$ & duplication & $8 \mathrm{p} 23.1$ & $\begin{array}{c}\text { coarctation of the } \\
\text { aorta }\end{array}$ & none & AGA & yes, preoperative \\
\hline $37, \mathrm{~m}$ & duplication & $8 \mathrm{p} 23.1$ & $\begin{array}{l}\text { coarctation of the } \\
\text { aorta }\end{array}$ & none & AGA & no \\
\hline $39, \mathrm{~m}$ & duplication & $8 \mathrm{p} 23.1$ & $\begin{array}{c}\text { pulmonary valve } \\
\text { stenosis }\end{array}$ & none & AGA & no \\
\hline $59, \mathrm{~m}$ & duplication & $8 \mathrm{p} 23.1$ & $\begin{array}{c}\text { pulmonary valve } \\
\text { stenosis }\end{array}$ & $\begin{array}{c}\text { left kidney } \\
\text { hydronephrosis }\end{array}$ & LGA & no \\
\hline
\end{tabular}

As subtle phenotypic characteristics are often difficult to be seen early on in life [2], especially in neonates, CHDs may be among the first symptoms in pathologies involving CHD as part of the clinical spectrum. Several studies have shown the importance of CNVs in a significant number of CHD patients $[1,6,8,10,11]$, but all existing studies focused their attention on children or fetuses, none trying to establish a diagnosis at birth or in the neonatal period. Early determination of a CHDs' genetic origin is important, as these children bare an increased risk of postoperative complications [12], and thus, the awareness of possible associated extracardiac abnormalities may be decisive for the optimal therapeutic management [6], be it surgical [13] or drug administration [3, 14]. Additionally, this diagnosis can be used for the correct genetic counseling of patients (i.e. in their adulthood) and their families [12].

CNVs pathogenicity is an intensively studied topic, as they are rather common among the general population, making up approximately 12\% [2] of an individual's genome, and yet several CNVs are considered potentially pathogenic in the context of patients with cardiovascular malformations, when exhibiting at least one of the following characteristics: (a) occurrence in a dosage sensitive CHD-causing gene with a similar phenotype, (b) occurrence in a region known to be disease associated, (c) occurrence in a gene-rich region, (d) large size of the deletion or duplication, (e) de novo or rare CNVs (occurring in $<1 \%$ of healthy individuals) [15].

In our study the MLPA detection rate was $16.67 \%$ (10/60 cases), comparable to the $3.2-33.33 \%$ rates indicated in previous studies $[1,6,8,10]$ that investigated $\mathrm{CNVs}$ associated to $\mathrm{CHD}$ in children, this variation being probably a consequence of patient selection criteria and MLPA kit used, rather than technique limitations. The apparently low detection rate should be interpreted in the light of current knowledge, as there may be up to 400 genes involved in CHD pathogenesis, many of which still not identified [12], therefore genetic testing of individuals with isolated apparently nonsyndromic CHDs is still a low-yield exercise [12], but improvements are predicted for the near future.

DiGeorge syndrome or 22q11.2 deletion syndrome is the second main cause of CHD $[1,16]$, and expectedly, it was the most frequently diagnosed disorder in our study, with an incidence of 5\% (3/60 patients), all being heterozygous. Our diagnosis rate was smaller than that of Monteiro et al.[1], but they included only syndromic patients. On the other hand, the studies of Sørensen et al.[6] and Campos et al.[8] reported detection rates of only $0.49 \%$ and $2.56 \%$ respectively, while that of El Malti et al.[10] identified no patients with 22q11.2 deletion syndrome. These results may be due to the method of selecting patients, as the studies cited above enrolled patients with both common and complex CHDs in syndromic as well as with isolated CHD, while our patients were all with apparently nonsyndromic CHDs. Because the P311 MLPA kit only contains three probes in the 22q11 DiGeorge region we opted for a second testing with the P250 
MLPA kit, and thus confirmed the diagnosis for our patients. If it were not for the CHD diagnosis, our patients might have left the hospital undiagnosed, as no other phenotypical modifications we observed (e.g. cleft lip/palate, facial dysmorphism) and other typical features of this syndrome, such as immune, developmental and behavioral deficits are expressed only after the neonatal period.

On the other hand, we cautiously interpreted the results of the 7 patients with GATA4 gene exon1 duplication, as MLPA single exon deletions/duplications in other pathologies have been previously reported as possible pitfalls [17] in the correct diagnosis of patients, and even according to the MLPA manufacturer's protocol these findings should be confirmed by long-range PCR and qPCR. Therefore, our patients will be subjected to further molecular testing, in order to correctly assess their diagnosis. The GATA4 gene encodes a protein involved in embryogenesis and myocardial differentiation and function, and its involvement in CHD occurrence was previously reported, both in syndromic patients (in 8p23.1 duplication syndrome [18] associated with TNKS1 and SOX7 genes) as well as non-syndromic CHDs associated to modifications in the gene's exon1 [19].

Our study is the first to study known clinically relevant CNVs in neonatal patients with apparently nonsyndromic CHDs, at least in Romania and Eastern Europe. One the other hand, weaknesses of our study might be the relatively small number of cases, and the fact that we used only one diagnosis technique, namely MLPA, even though we used multiple MLPA SALSA kits.

\section{Conclusions}

Our study indicates that the multiplex ligation-dependent probe amplification technique can be used as a first-tier screening tool for patients with apparently nonsyndromic congenital heart disease, providing early and correct diagnosis of known clinically relevant copy number variations with possible future clinical and therapeutic implications in these neonates.

Acknowledgments: This work was supported by the University of Medicine and Pharmacy of Tîrgu Mureș Research Grant number 15609/11/29.12.2017.

\section{References}

1.MONTEIRO, R., DE FREITAS, M., VIANNA, G., DE OLIVEIRA, V., PIETRA, R., FERREIRA, L., ROCHA, P., DA S., GONÇALVES, M., DA C., CÉSAR, G., DE S., LIMA, J., MEDEIROS, P., MAZZEU, J., JEHEE, F., Mol. Syndromol., 8, no. 5, 2017 , p. 227.

2.LANDER, J., WARE, S.,M., Curr. Genet. Med. Rep., 2, 2014, p. 168.

3.CUCEREA, M., SIMON, M., MOLDOVAN, E., UNGUREANU, M., MARIAN, R., SUCIU, L., J. Crit. Care. Med., 2, no. 4, 2016 , p.185.

4.COWAN, J.,R., WARE, S.,M., Clin. Perinatol., 42, no. 2, 2015, p. 373.

5.PIERPONT, M., E., BASSON, C., T., BENSON, D., W., JR., GELB, B., D., GIGLIA, T., M., GOLDMUNTZ, E., MCGEE, G., SABLE, C., A., SRIVASTAVA, D., WEBB, C., L., Circulation. 115, no. 23, 2007, p. 3015.

6.SØRENSEN, K., M., EL-SEGAIER, M., FERNLUND, E., ERRAMI, A., BOUVAGNET, P., NEHME, N., STEENSBERG, J., HJORTDAL, V., SOLlER, M., BEHJATI, M., WERGE, T., KIRCHOFF, M., SCHOUTEN, J., TOMMERUP, N., ANDERSEN, P,. S., LARSEN, L,. A., Am. J. Med. Genet. A. 158A, no. 4, 2012, p. 720.

7.RICHARDS, A., GARG, V., Curr. Cardiol. Rev. 6, no. 2, 2010, p. 91.

8.CAMPOS, C., ZANARDO, E., DUTRA, R., KULIKOWSKI, L., KIM, C., Arq. Bras. Cardiol. 104, no. 1, 2015 , p. 24.

9.LUBCHENCO, L., O., HANSMAN, C., DRESSLER, M., BOYD, E., Pediatrics., 32, 1963, p.793.

10.EL MALTI, R., LIU, H., DORAY, B., THAUVIN, C., MALTRET, A., DAUPHIN, C., GONÇALVES-ROCHA, M., TEBOUL, M., BLANCHET, P., ROUME, J., GRONIER, C., DUCREUX, C., VEYRIER, M., MARÇON, F., ACAR, P., LUSSON, J., R., LEVY, M., BEYLER, C., VIGNERON, J., CORDIER-AlEX, M., P., HEITZ, F., SANLAVILlE, D., BONNET, D., BOUVAGNET, P., Eur. J. Hum. Genet., 24, no. 2, 2016, p. 228.

11.CRAUCIUC, G., TRIPON, F., BOGLIŞ, A., FĂGĂRĂŞAN, A., BĂNESCU, C., Rev. Romana. Med. Lab., 26, no. 4, 2018 , p. 461.

12.BLUE, G., KIRK, E., GIANNOULATOU, E., SHOLlER, G., DUNWOODIE, S., HARVEY, R., WINLAW, D., J. Am. Coll. Cardiol., 69, no. 7, 2017 , p. 859.

13.ALSOUFI, B., GILlESPIE, S., MAHLE, W., T., DESHPANDE, S., KOGON, B., MAHER, K., KANTER, K., Semin. Thorac. Cardiovasc. Surg., 28, no. 1, 2016, p. 105 .

14.MOLDOVAN, E., CUCEREA, M., J. Crit. Care. Med., 1, no. 1, 2015, p. 28.

15.KEARNEY, H., M., THORLAND, E., C., BROWN, K., K., QUINTERO-RIVERA, F., SOUTH, S., T., Genet. Med., 13, no. 7, 2011 , p. 680.

16.PANZARU, M., RUSU, C., VOLOSCIUC, M., BRAHA, E., BUTNARIU, L., GRAMESCU, M., POPESCU, R., CABA, L., BUJORAN, C., IVANOV, I., MACOVEI, M., SIRETEANU, A., COVIC, M., GORDUZA, V., Rev. Rom. Med. Lab., 20, no. 3/4, 2012 , p. 265.

17.KIM, M., CHO, S., CHAE, J., LIM, B., LEE, J., LEE, S., SEO, S., PARK, H., CHO, A., KIM, S., KIM, J., PARK, S., SEONG, M., J. Mol. Diagn., 18, no. 2, 2016, p. 253.

18.BARBER, J., ROSENFELD, J., GRAHAM, J., KRAMER, N., LACHLAN, K., BATEMAN, M., COLLINSON, M., STADHEIM, B., TURNER, C., GAUTHIER, J., REIMSCHISEL, T., QURESHI, A., DABIR, T., HUMPHREYS, M., MARBLE, M., HUANG, T., BEAL, S., MASSIAH, J., TAYLOR, E., WYNN, S., Am. J. Med. Genet. A., 167A, no. 9, 2015, p. 2052.

19.SHAKER, O., OMRAN, S., SHARAF, E., HEGAZY, A., G., MASHALY, M., GABOON, E., A., N., Turk. J. Med. Sci., 47, no. 1, 2017, p. 217.

Manuscript received: 23.05 .2019 
